The International Journal of Indian Psychology: Volume: 01 | Issue: 04 No. 2 | ISSN 2348-5396

\title{
Happiness and Wellbeing
}

\author{
Ruchi Sundriyal*, Dr. Ravindra Kumar**
}

\begin{abstract}
Happiness is a mental or emotional state of well-being characterized by positive or pleasant emotions ranging from contentment to intense joy. Happiness as a concept seems to be readily embraced by the majority of people and appears to be more valued than the pursuit of money, moral goodness or going to heaven. Philosophers and religious thinkers often define happiness in terms of living a good life, or flourishing, rather than simply as an emotion. Happiness economics suggests that measures of public happiness should be used to supplement more traditional economic measures when evaluating the success of public policy. Happy people are healthy people. Happy people live longer and enjoy a greater quality of life. They function at a higher level, utilizing their personal strengths, skills, and abilities to contribute to their own wellbeing as well as that of others and society. Wellbeing is a contented state of being happy and healthy and prosperous. Psychological well-being refers to how people evaluate their lives. These evaluations may be in the form of cognitions or in the form of affect. The cognitive part is an information based appraisal of one's life that is when a person gives conscious evaluative judgments about one's satisfaction with life as a whole. Most people evaluate their life as either good or bad, so they are normally able to offer judgments. People invariably experience moods and emotions which have a positive effect or a negative effect. We can define psychological well-being in terms of internal experience of the respondent and their own perception of their lives. People have a level of subjective well-being even if they do not often consciously think about it, and the psychological system offers virtually a constant evaluation of what is happening to the person.
\end{abstract}

KEYWORDS: Happiness, wellbeing, life satisfaction, cognitions

\section{INTRODUCTION}

The basic tendency of human being is to express the emotions in his environment towards the stimulus. Basically, we express our emotions in two ways as positive or negative form.

*Indian Institute of Psychology, NOIDA (U.P.)

**Department of Psychology, Mewar University, Chittorgarh (Rajasthan)
(C) 2014 www.ijip.in
July-September 2014
19 | P a g e 
When we feel pleasure experience in our environment we express positive emotions and when we feel sad experience in our environment we express negative emotions. The mental state of expression of positive emotions in a pleasure form may be called happiness. Expression of positive emotions depends on the positive functioning of physical, psychological and social functioning. In other words we can say that happiness is the combination of physical, psychological and social wellbeing. Happiness has been a topic of interest for many centuries, starting with ancient Greek philosophy, post-enlightenment western-european moral philosophy to current quality-of-life and well-being research in social, political and economic sciences.

A Philosopher and Religious thinkers often define happiness in terms of living a good life, or flourishing, rather than simply as an emotion. A Sociologist defines happiness in social aspects and relationships in the society. A Medical professional defines happiness as a state of complete physical health rather than simply as an emotion. An Economist defines happiness as a state of good economic condition rather than simply as an emotion. A Psychologist defines happiness as a good mental health and psychological wellbeing. In short, it can be concluded that meaning of happiness and wellbeing is different according to experts from different areas and specialization. As a scientific enterprise, positive psychology focuses on understanding and explaining happiness and subjective well-being and accurately predicting factors that influence such states. As a clinical Endeavour, positive psychology is concerned with enhancing subjective well-being and happiness, rather than remediating deficits.

Seligman (2002) in his book Authentic Happiness classifies positive emotions into three categories: those associated with the past, the present and the future. Positive emotions associated with the future include optimism, hope, confidence, faith and trust. There are two distinct classes of positive emotions concerned with the present: momentary pleasures and more enduring gratifications. The pleasures include both bodily pleasures and higher pleasures. Bodily pleasures come through the senses. Feelings that come from sex, beautiful perfumes and delicious flavors fall into this category. In contrast higher pleasures come from more complex activities and include feelings such as bliss, glee, comfort, ecstasy and ebullience. Gratifications differ from pleasures in that they entail states of absorption or flow that come from engagement in activities which involve using our unique signature strengths. Sailing, teaching and helping others are examples of such activities. Signature strengths are personal traits associated with 
The International Journal of Indian Psychology: Volume: 01 | Issue: 04 No. 2 | ISSN 2348-5396

particular virtues defined in the values in action classification of strengths (Peterson and Seligman, 2001).

Happiness is a mental or emotional state of well-being characterized by positive or pleasant emotions ranging from contentment to intense joy. A variety of biological, psychological, religious and philosophical approaches have striven to define happiness and identify its sources. Many theories of happiness have been proposed since Aristotle's brilliant insights. These theories can be categorized into three groups: (1) need and goal satisfaction theories, (2) process or activity theories, and (3) genetic and personality predisposition theories. The first constellation of theories centers on the idea that the reduction of tensions (e.g., the elimination of pain and the satisfaction of biological and psychological needs) leads to happiness. Freud's pleasure principle and Maslow's (1970) hierarchical needs model represent this approach. In support of this view, Omodei and Wearing (1990) found that the degree to which individuals' needs were met was positively associated with the degree of their life satisfaction.

\section{BASIC INTERLINKED ELEMENTS OF HAPPINESS \& WELLBEING}

Happiness is a mental or emotional state of well-being characterized by positive or pleasant emotions. A variety of biological, psychological, religious and philosophical approaches have striven to define happiness and identify its sources. When we analyzed these approaches we find that happiness and wellbeing is a state of mind developed by three basic interlinked elements such as physical or structural health, psychological or mental health and social health. These three elements are interlinked and affect each other. If we find complete ourself on physical element, we reach to second element as mental health and in the last after completing both physical and mental health; we will reach to the social element which is known as social health.

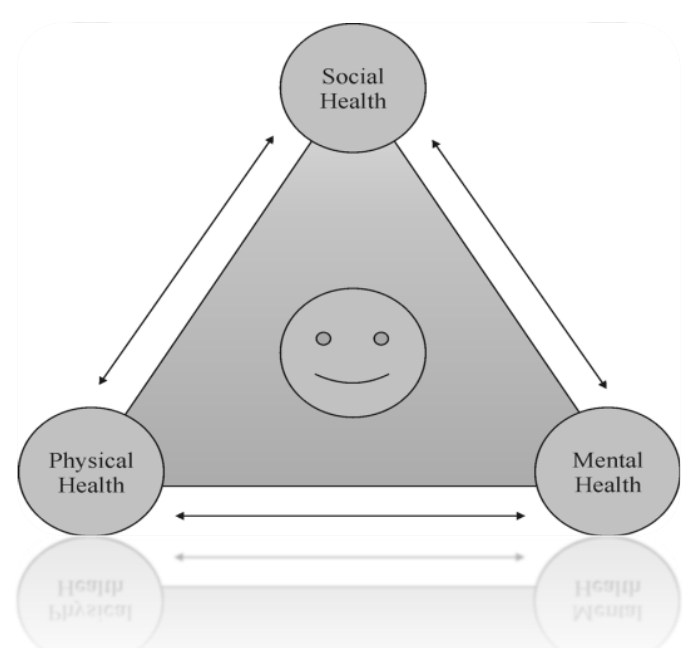

If we construct a hierarchical structure of the elements of happiness \& wellbeing it may be defined as the three basic interlinked elements such as physical health, psychological health and social health. Happiness and wellbeing may be defined with the three basic elements are as follow:

[Figure I: Basic Interlinked Elements of Happiness \& Wellbeing] 
The International Journal of Indian Psychology: Volume: 01 | Issue: 04 No. 2 | ISSN 2348-5396

\section{Physical or Structural Health:}

Physical or Structural health can be determined by considering someone's height/weight ratio, their body mass index, their resting heart rate and recover time after exercise. Physical health has been the basis for active living campaigns and the many nutrition drives that have swept the industrialized world.

\section{Psychological or Mental Health:}

Psychological or Mental health is a state of well-being in which we realize our abilities, can cope with life's normal stresses, and can work regularly and productively. If someone is suffering from mental health difficulties, they may attend counseling or psychotherapy to 'unlock' previous emotional turmoil and then actually use their past emotional trauma in order to grow and develop their emotional intelligence, thereby improving their overall emotional health.

\section{Social Health:}

Social determinants of health are the economic and social conditions and their distribution among the population that influence individual and group differences in health status. According to some viewpoints, these distributions of social determinants are shaped by public policies that reflect the influence of prevailing political ideologies of those governing a jurisdiction.

After analyzed the basic interlinked elements we reach on a conclusion that physical and psychological health is the foundation element of social health. Social health leads to the stage of wellbeing and happiness. These three elements play an important role in the development of positive emotions, strength, happiness and wellbeing.

World Health Organization defined the concept of health that "Health is a state of complete physical, mental and social well-being and not merely the absence of disease or infirmity" (WHO, 1948). The World Health Organization addressed the interdependence of physical health and social-emotional well-being along with the appreciation of health as more than freedom from impairment. Components of health and well-being are mutually interrelated (WHO, 1948).

\section{MASLOW'S HIERARCHICAL NEEDS MODEL}

Maslow's hierarchy of needs concept assumes that lower level needs must be satisfied or at least relatively satisfied before higher level needs become motivators. These needs, which Maslow often referred to as basic needs, can be arranged on a hierarchy or staircase, with each ascending 
step representing a higher need but one less basic to survival. Lower level needs have prepotency over higher level needs; that is, they must be satisfied or mostly satisfied before higher level needs become activated. For example, anyone motivated by esteem or self-actualization must have previously satisfied needs for food and safety. Hunger and safety, therefore, have prepotency over both esteem and self-actualization.

Maslow (1970) listed the following needs in order of their prepotency: physiological, safety, love and belongingness, esteem, and self-actualization:

Physiological Needs: The most basic needs of any person are physiological needs, including food, water, oxygen, maintenance of body temperature, and so on. Perpetually hungry people are motivated to eat — not to make friends or gain self-esteem. They do not see beyond food, and as long as this need remains unsatisfied, their primary motivation is to obtain something to eat (Maslow, 1970).

Safety Needs: When people have partially satisfied their physiological needs, they become

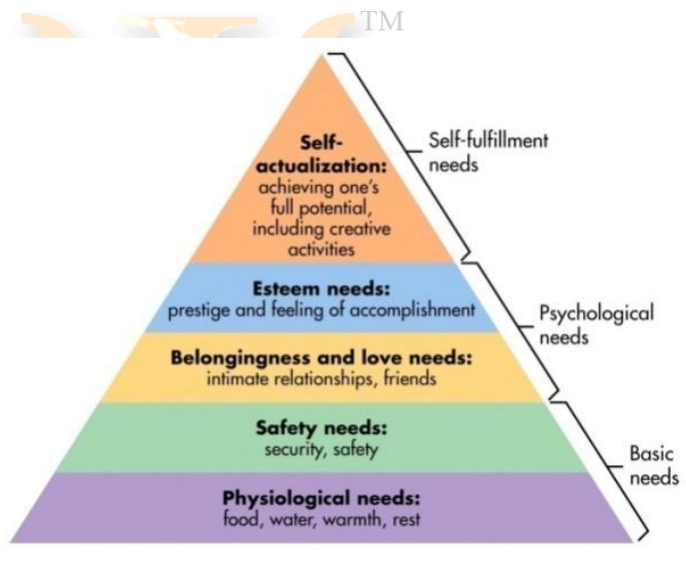
motivated by safety needs, including physical security, stability, dependency, protection, and freedom from threatening forces lsuch as war, terrorism, illness, fear, anxiety, danger, chaos, and natural disasters. The needs for law, order, and structure are also safety needs (Maslow, 1970).

\section{[Figure II: Maslow's (1970) Hierarchical Needs}

\section{Model]}

Love and Belongingness Needs: After people partially satisfy their physiological and safety needs, they become motivated by love and belongingness needs, such as the desire for friendship; the wish for a mate and children; the need to belong to a family, a club, a neighborhood, or a nation. Love and belongingness also include some aspects of sex and human contact as well as the need to both give and receive love (Maslow, 1970).

Esteem Needs: To the extent that people satisfy their love and belongingness needs, they are free to pursue esteem needs, which include self-respect, confidence, competence, and the knowledge that others hold them in high esteem. Maslow (1970) identified two levels of esteem needs - reputation and self-esteem. 
The International Journal of Indian Psychology: Volume: 01 | Issue: 04 No. 2 | ISSN 2348-5396

Self-Actualization Needs: When lower level needs are satisfied, people proceed more or less automatically to the next level. However, once esteem needs are met, they do not always move to the level of self-actualization.

If we analyze the Maslow's Hierarchical Needs Model, we find that happiness and wellbeing is related to the fulfillment of needs. Maslow told three types of need such as basic needs, psychological needs and self-fulfillment need. When we completed and fulfillment these needs hierarchically we go to on a last stage that may be known as happiness and wellbeing. In relation to the concept of psychological well-being, Ryff (1989) proposes a multidimensional model composed of 6 different dimensions: Self-acceptance, Positive relations with others, Autonomy, Environmental mastery, Purpose in life and Personal growth. These 6 dimensions of psychological well-being can be defined as follows:

Self-acceptance: This is a key part of well-being and concerns the positive opinion a person has of himself.

Positive relationships with others: These include the fortitude, pleasures and human delights that come from close contact with others, from intimacy and love. The importance of having positive relationships with other people is repeatedly emphasized in definitions of psychological well-being (Ryff and Singer, 1996).

Autonomy: This refers to a person's ability to march to his own drum and to pursue personal convictions and beliefs, even if these go against accepted dogma or conventional wisdom.

Environmental mastery: This is another essential factor in well-being and concerns the challenge of a person mastering the environment around him. This ability requires the skills of creating and sustaining environments that are beneficial to a person (Ryff and Singer, 2003).

Purpose in life: This is a person's ability to find a meaning and a direction in his own experiences, and to propose and set goals in his life (Ryff and Singer, 2003).

Personal growth: This factor concerns a person's ability to realize his own potential and talent and to develop new resources. It also frequently involves encounters with adversity that require one to dig deeply to find one's inner strength (Ryff and Singer, 2003).

The six dimensions given by Ryff and Singer in relation to psychological well-being selfacceptance, autonomy, environmental mastery, purpose in life, personal growth are near the stage of self actualization told by Maslow (1970) but there is a lack of hierarchy of levels of wellbeing. 
The International Journal of Indian Psychology: Volume: 01 | Issue: 04 No. 2 | ISSN 2348-5396

\section{HIERARCHY OF HAPPINESS \& WELLBEING}

Maslow's Hierarchical Needs Model emphasis on fulfillment of needs only but it is to near stage of happiness and wellbeing. After analysis the Maslow's model we find that only satisfaction of needs is not enough but the gain of total wellbeing also. Need and goal satisfaction theorists argue that the reduction of tension and satisfaction of biological and psychological needs and

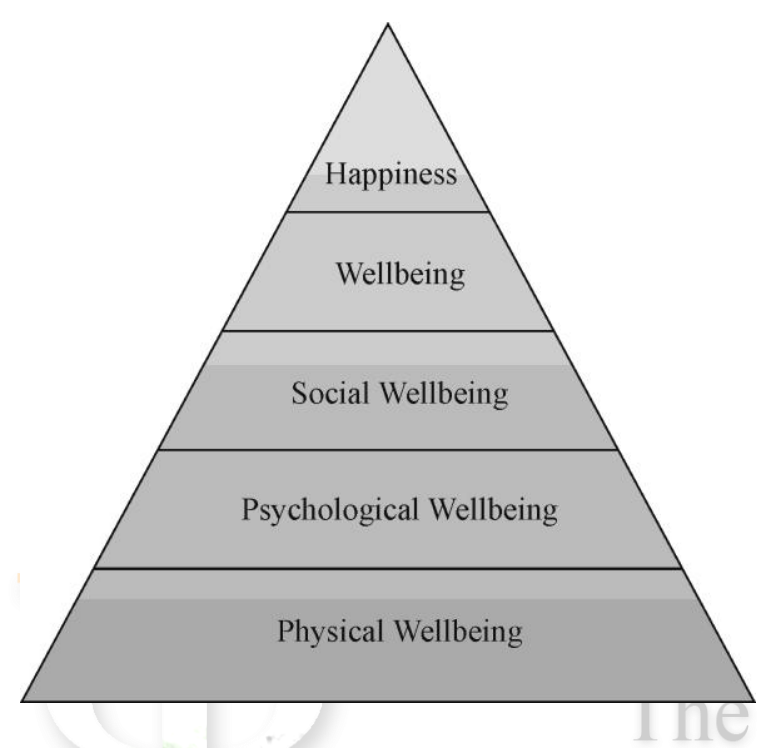
goals will cause happiness. One implication of tension-reduction theories is that happiness occurs after needs is met and goals are fulfilled. In other words, happiness is a desired end state toward which all activity is directed. We may structure the following stages in relation to happiness and wellbeing:

\section{[Figure III: Hierarchy of Happiness \& Wellbeing]}

Physical Wellbeing: In the hierarchy the first level is physical well-being. Physical wellbeing has been defined by measuring health status, functional outcome, or quality of life. Physical health relates to anything concerning our bodies as physical entities. Physical health has been the basis for active living campaigns and the many nutrition drives that have swept the industrialized world. Another term for physical health is physical wellbeing. Physical wellbeing is defined as something a person can achieve by developing all health-related components of his/her lifestyle.

Psychological Wellbeing: In the hierarchy the second level is psychological wellbeing. Psychological wellbeing may be defined by the proper functioning of psychological system. Positive functioning encompasses six dimensions of psychological well-being: self-acceptance, positive relations with others, personal growth, purpose in life, environmental mastery, and autonomy. Each dimension of psychological wellbeing contributes to mental health.

Social Wellbeing: In the hierarchy third level is social wellbeing. Social Wellbeing refers to our ability to interact successfully within a community and throughout a variety of cultural contexts while showing respect for ourselves and others. Social Wellbeing encompasses our interpersonal relationships, social support networks and community engagement. Thus, social wellbeing is defined as a positive functioning includes social challenges and tasks, and proposed five 
The International Journal of Indian Psychology: Volume: 01 | Issue: 04 No. 2 | ISSN 2348-5396

dimensions of social well-being. Thus, the triad comprising mental health includes the subjective feeling and functional states of emotional, psychological, and social well-being.

Wellbeing: In the hierarchy fourth level is wellbeing. Positive psychological definitions of wellbeing generally include some general characteristics such as the active pursuit of well-being, a balance of attributes, positive affect or life satisfaction, prosocial behaviour, multiple dimensions and personal optimization. Thus, wellbeing is may be defined as a combination of positive functioning of physical, psychological, emotional, social, spiritual, economical system.

Happiness: In the hierarchy fifth level is happiness. It is the level where positive emotions arise. Positive emotions associated with the future include optimism, hope, confidence, faith and trust. It is the level of being happiness. Happiness is a mental or emotional state of well-being characterized by positive or pleasant emotions ranging from contentment to intense joy.

\section{CONCLUSION}

In conclusion we can say that happiness is a mental or emotional state of well-being characterized by positive or pleasant emotions ranging from contentment to intense joy. A variety of biological, psychological, religious and philosophical approaches have striven to define happiness and identify its sources. The basic tendency of human being is to express the emotions in his environment towards the stimulus. Basically, we express our emotions in two ways as positive or negative form. When we feel pleasure experience in our environment we express positive emotions and when we feel sad experience in our environment we express negative emotions. The mental state of expression of positive emotions in a pleasure form may be called happiness. When we analyzed these approaches we find that happiness and wellbeing is a state of mind developed by three basic interlinked elements such as physical or structural health, psychological or mental health and social health. If we construct a hierarchical structure of happiness \& wellbeing it may be defined as the three basic interlinked elements such as physical health, psychological health and social health. After analyzed the basic interlinked elements we reach on a conclusion that physical and psychological health is the foundation element of social health. Social health leads to the stage of wellbeing and happiness. These three elements play an important role in the positive development of strength such as happiness and wellbeing. World Health Organization defined the concept of health that "Health is a state of complete physical, mental and social well-being and not merely the absence of disease or 
The International Journal of Indian Psychology: Volume: 01 | Issue: 04 No. 2 | ISSN 2348-5396

infirmity" (WHO, 1948). Maslow's hierarchy of needs concept assumes that lower level needs must be satisfied or at least relatively satisfied before higher level needs become motivators. If we analyze the Maslow's Hierarchical Needs Model, we find that happiness and wellbeing is related to the fulfillment of needs. Maslow told three types of need such as basic needs, psychological needs and self-fulfillment need. When we completed and fulfillment these needs hierarchically we go to on a last stage that may be known as happiness and wellbeing. In relation to the concept of psychological well-being, Ryff (1989) proposes a multidimensional model composed of 6 different dimensions: Self-acceptance, Positive relations with others, Autonomy, Environmental mastery, Purpose in life and Personal growth. The six dimensions given by Ryff and Singer in relation to psychological well-being self-acceptance, autonomy, environmental mastery, purpose in life, personal growth are near the stage of self actualization told by Maslow (1970) but there is a lack of hierarchy of levels of wellbeing. In conclusion it can be said that happiness and wellbeing is the mental state of expression of positive emotions of the positive functioning and wellbeing of physical, psychological and social functioning.

\section{REFERENCES}

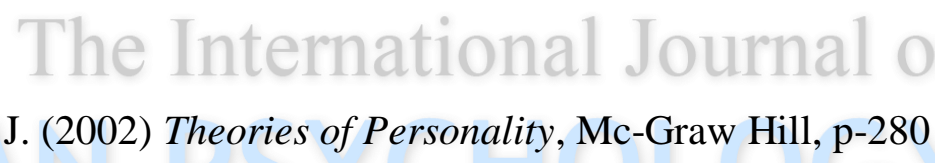

1. Feist, Jess and Feist Gregory J. (2002) Theories of Personality, Mc-Graw Hill, p-280

2. Maslow, A. H. (1970) Motivation and Personality, New York: Harper and Row.

3. Omodei, M. M., \& Wearing, A. J. (1990) Need satisfaction and involvement in personal projects: Toward an integrative model of subjective well-being, Journal of Personality and Social Psychology, Vol. (59) 762-769

4. Peterson, C. and Seligman, M. (2001) Values in Action Inventory of Strengths (VIA-IS) Manual

5. Ryff, C. (1989) Happiness is everything, or is it? Explorations on the meaning of psychological well-being, Journal of Personality and Social Psychology, Vol (57) 10691081

6. Ryff, C. D. and Singer, B (1996) Psychological well-being: meaning, measurement, and implications for psychotherapy research, Psychotherapy \& Psychosomatic, Vol (65) 1423

7. Ryff, C. D. and Singer, B. (2003) Ironies of the human condition: Well-being and health on the way to mortality. In L.G. Aspinwal and U. M. Staudinger (Eds.) A Psychology of Human Strengths: Fundamental questions and future directions for a positive psychology, pp. 271-287

8. Seligman, M. (2002) Authentic Happiness: Using the New Positive Psychology to Realise your Potential for Lasting Fulfillment, New York: Free Press

9. World Health Organization (1948) Constitution of the World Health Organization, p-2 